\title{
Analysis on Three Dimensional Flow of Direct-injection Diesel Engine for Different Piston Configuration using CFD
}

\author{
G. Sucharitha* and A. Kumaraswamy \\ Department of Mechanical Engineering, Bharath University, Chennai, India; \\ saisuchi_2002@yahoo.com, aluri_ka@yahoo.com
}

\begin{abstract}
Recent years have witnessed rapid developments in the field of IC engines. Today both the manufacturers and the customers are looking for low polluting and better efficient engines. Basically, the in-cylinder gas motion affects the performance of the engine. Increase in combustion efficiency obviously results in fuel economy and low pollutant emissions. So, it is necessary to have a better control over in-cylinder gas motion. The main objective of this project is three dimensional flow calculations of the compression stroke of a four-valve direct-injection Diesel engine for different Piston configuration. A limited number of validation calculations of the Intake stroke and compression stroke were performed in order to explore the limits of Computational Fluid Dynamics representation of the in-cylinder flow. In the main study, the flow characteristics such as Swirl Ratio, Radial Velocity field and Tangential Velocity field inside the engine cylinder equipped with different piston configurations were analyzed in detail. The results confirmed that the piston geometry had little influence on the in-cylinder flow during the Intake stroke and the first part of Compression stroke. The bowl shape plays a significant role near TDC and in the early stage of the expansion stroke by controlling the turbulence velocity fields.
\end{abstract}

Keywords: In Line Cylinder Gas Motion, CFD

\section{Introduction}

Computational Fluid Dynamics (CFD) is a sophisticated computational-based design and analysis technique that enables to study the dynamics of fluid. CFD technique is applied to simulate the flow of gases and liquids, heat and mass transfer, moving bodies, multiphase physics, chemical reaction, fluid-structure interaction and acoustics through computer modeling. In the systems which are difficult to model a prototype or test through experimentation, CFD analysis facilitates to virtually move inside the design and check its performance $[3,5]$. Now-a-days Internal Combustion engines are playing a vital role in the automobile industry. As a result of this, the development of Compression Ignition (CI) engines is bringing an industrial revolution because of their wide usage in heavy duty engines. The CI engines are undergoing various modifi-

\footnotetext{
* Corresponding author:

G.Sucharitha (saisuchi_2002@yahoo.com)
}

cations based on their piston-cylinder geometry, fuel injection systems and combustion chambers $[10,11$, $12,13]$, in order to improve their performance and to reduce the emission levels. Various changes such as intake and exhaust valve arrangements, modification of the piston face are being made to modify the combustion chamber. The present study deals with the modification of the piston face. Building up a real prototype for piston in a cylinder and experimenting it, is much expensive and also consumes a lot of time. Hence, a virtual prototype of the piston in a cylinder is created and analyzed using CFD software package.

\subsection{In-Cylinder Flow in Direct Injection}

\section{(DI) Diesel Engine}

The in-cylinder flow describes the motion of air within the cylinder of the diesel engine, during the four strokes 
of its operation. During the suction stroke, the air is drawn into the cylinder and then it is compressed during the compression stroke. When the power stroke is about to start near TDC, fuel is injected into the cylinder. The air at high temperature gets mixed up with the vaporized fuel and self ignition of fuel takes place during the power stroke. After the expansion, the gases are removed out of the cylinder in the exhaust stroke [1]. The present work deals with the air flow during the suction and compression strokes, and the effect of the combustion chamber design on the flow.

\subsection{Software Tools}

Gambit is a pre-processor by which a virtual model is created for the given problem. Pre-processing consists of the input of a flow problem to a CFD program by means of an operator-friendly interface and the subsequent transformation of this input into a form suitable for use by the solver. FLUENT is a state-of-the-art computer program for modeling fluid flow and heat transfer in complex geometries. FLUENT provides complete mesh exibility, solving flow problems with unstructured meshes that can be generated about complex geometries with relative ease [7].

\section{Case Description}

Three-dimensional flow calculations of the intake and compression stroke of a four valve direct-injection Diesel Engine have been carried out with different combustion chambers. A limited number of validation calculations of the compression stroke were first performed in order to explore the limits of CFD representation of the in-cylinder flow. The three-dimensional model is reasonably accurate for crank angle around TDC. In general it performs better for low swirl combustion chambers while turbulence velocities are under predicted when squish effects are important $[3,4,8]$.

The flow characteristics inside the engine cylinder equipped with different piston configurations were studied. The results confirmed that the piston geometry had little influence on the in cylinder flow during the intake stroke and the first part of compression stroke. The bowl shape place a significant role at TDC and early stage of expansion stroke by controlling turbulent velocity field. The shapes are represented for the geometries usually employed for the optimum combustion chambers in real engines [3]. Existing Piston is a flat piston. Piston A is a Shallow depth chamber (Figure 1). Piston B is a Toroidal chamber (Figure 2).

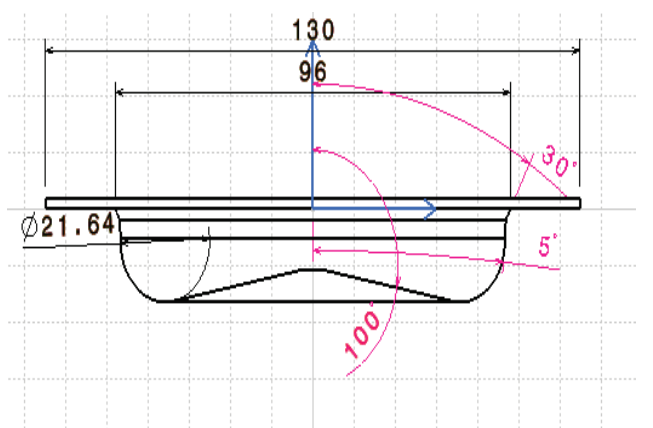

Figure 1. Shallow DepthChamper Piston A.

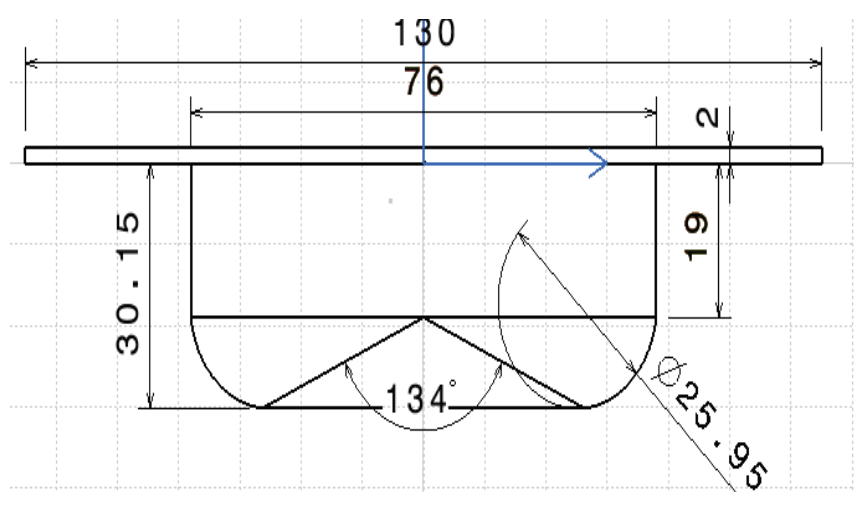

Figure 2. Toroidal Chamber Piston B.

\section{Methodology}

The modeling and analysis of the piston configuration has been done by using the CFD software packages. The software packages GAMBIT and FLUENT 6.1 were used. GAMBIT was used for modeling and meshing the Piston. Fluent was used for analyzing the model which has been done in the GAMBIT. General program structure of GAMBIT and FLUENT packages.

The work has been carried out in the following stages (Figure 3).

- Modeling the piston using GAMBIT

- Analyzing the piston in FLUENT

\section{Result}

The combustion chambers with three different pistons were modeled in GAMBIT and the geometry of the pistons has been pre-processed. The analysis of the combustion chambers and the post-processing of the results have been done successfully using FLUENT. The in-cylinder air flow characteristics have been analyzed in detail during the suction and compression strokes at different crank angles. 
The contours of Pressure, Temperature, Velocity, Radial velocity field and the Tangential velocity field have been processed for the different combustion chambers, at different crank angles. The swirl ratio at various crank angles has been calculated successfully for the three combustion chambers. The following Figure 4 to 10 depict the details the development of the project.

Similarly the contour plot \& parameter plots are found for both Piston B \& Existing Piston. The parameter analyses are given as Table 1,2 and 3.

Using the Table data the graphs are plotted (Figures 11, $12 \& 13)$.

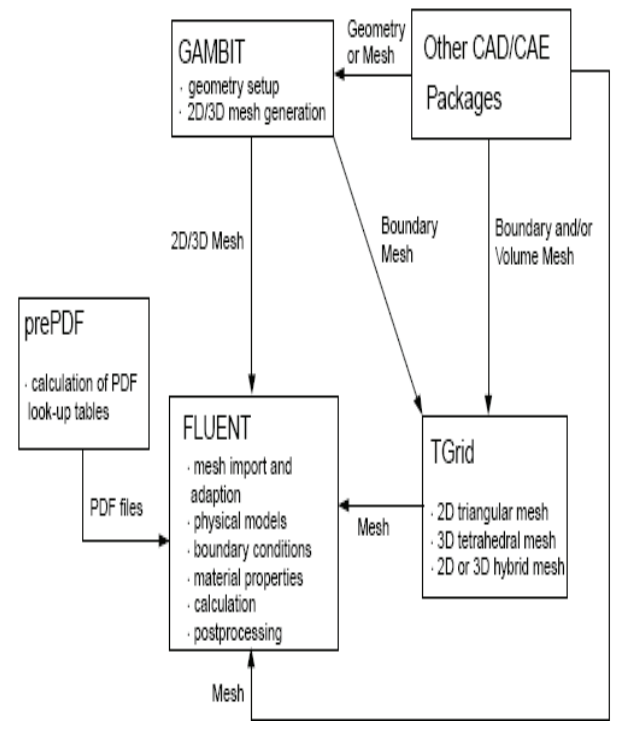

Figure 3. Basic Program Structure.
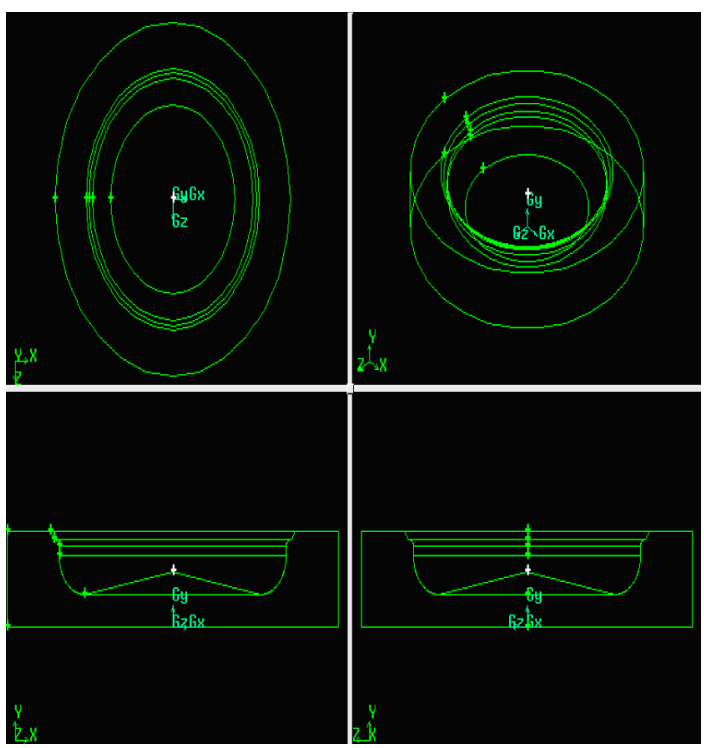

Figure 4. Wire frame model of the piston A in gambit.

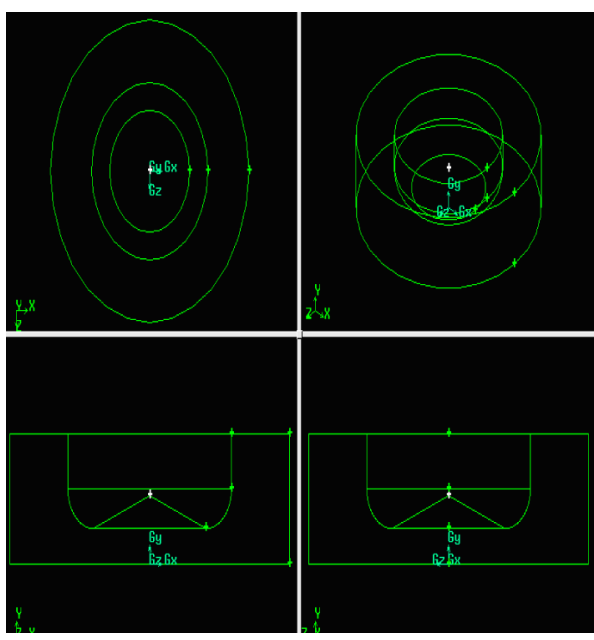

Figure 5. Wire frame model of the piston B in gambit.

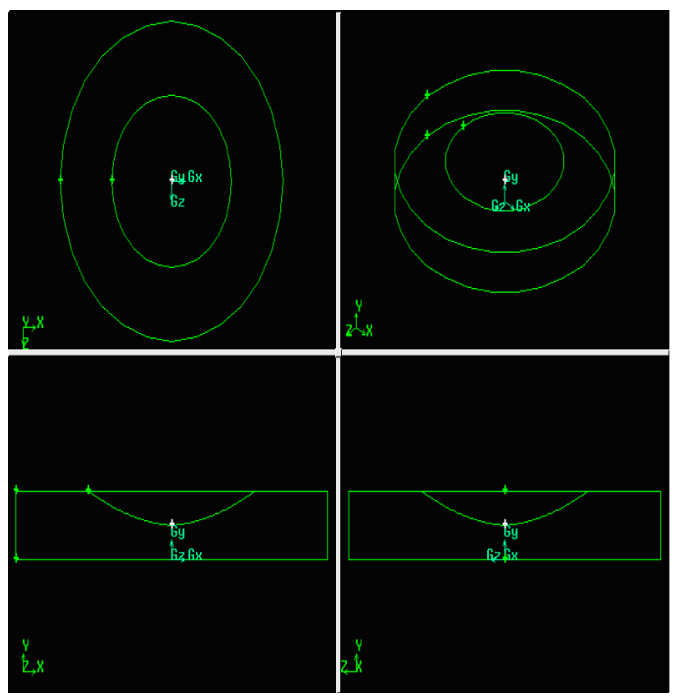

Figure 6. Wire frame model of the existing piston in gambit.

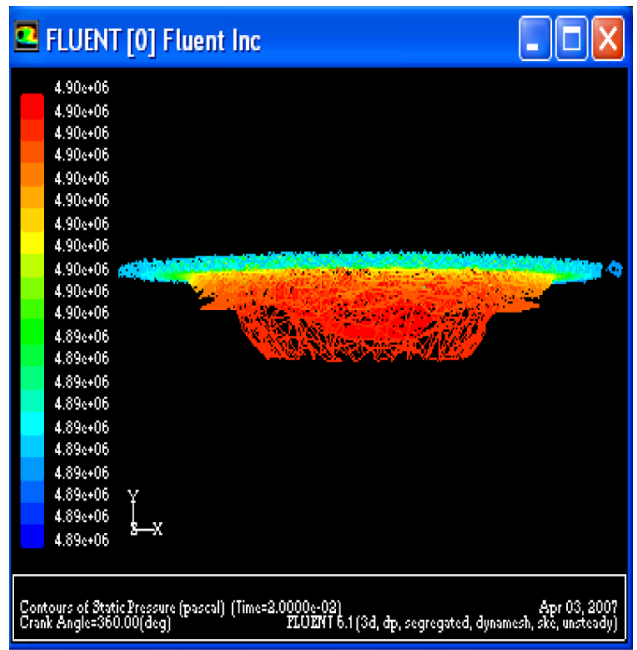

Figure 7. Contours of temperature for piston A. 


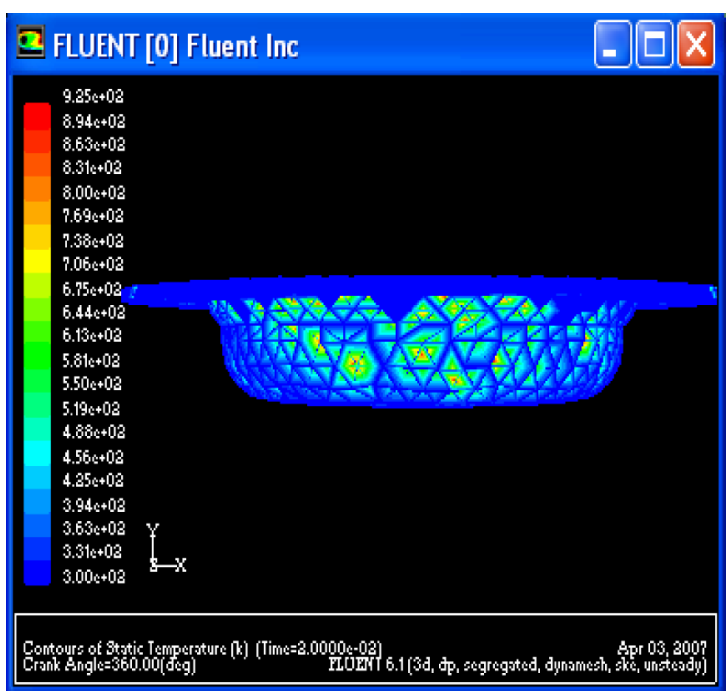

Figure 8. Velocity vectors of piston A.

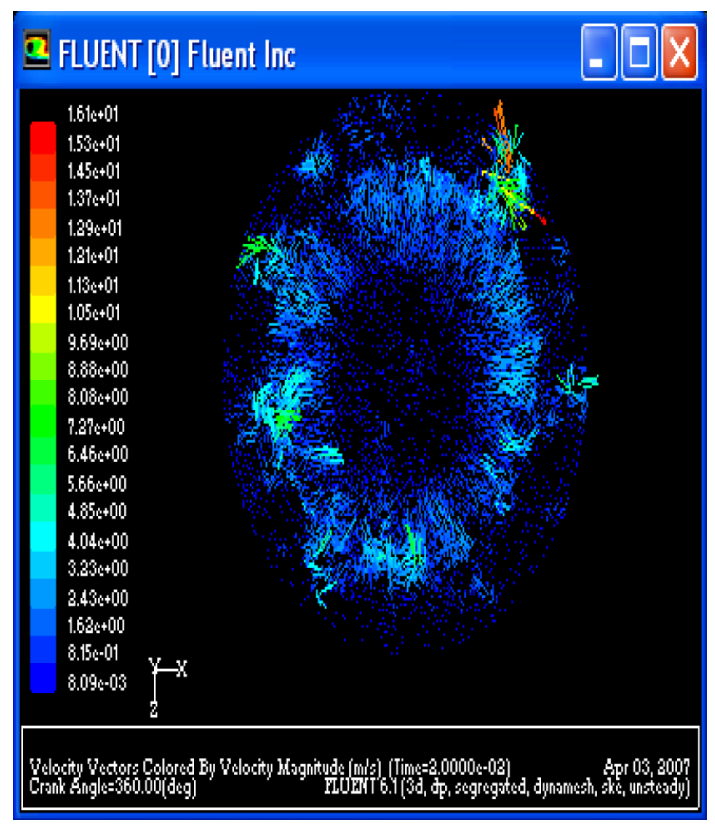

Figure 9. Radial velocity field of piston A.

\section{Conclusion}

The In-Cylinder air flow characteristics of the intake and the compression strokes of a DI Diesel Engine have been analyzed. The resulting swirl ratio was calculated for different combustion chamber shapes. During the intake stroke, the shape of the piston does not play any significant role. An increase in the swirl level is observed in the second part of the intake stroke. In the compression stroke, the piston geometry had a significant influence on the air flow characteristics, and a greater effect is observed as the piston approached TDC.

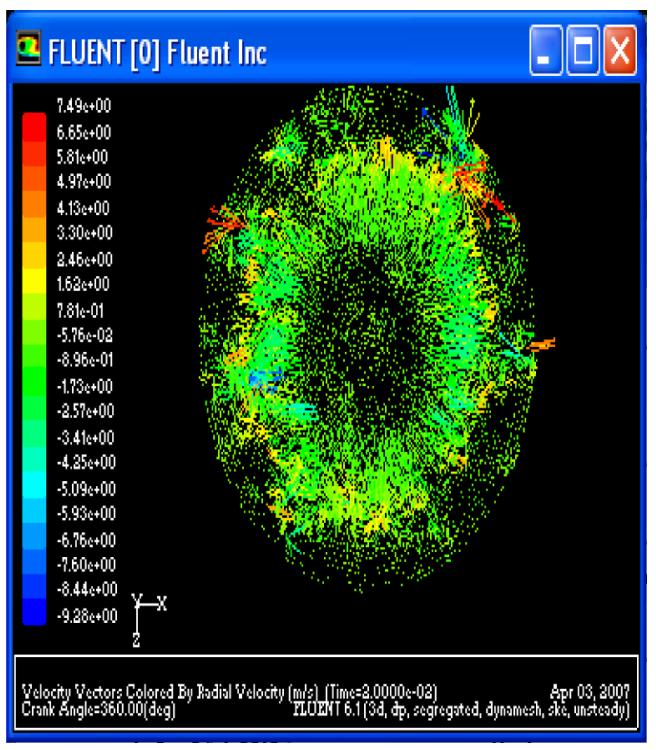

Figure 10. Tangential velocity field of piston A.

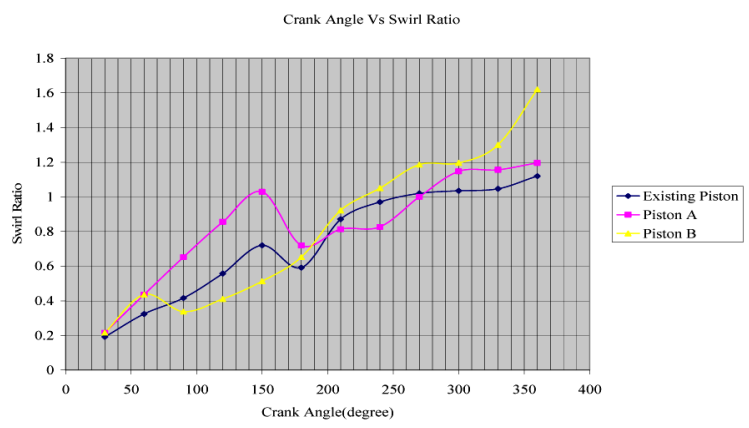

Figure 11. Crank angle vs. swirl ratio.

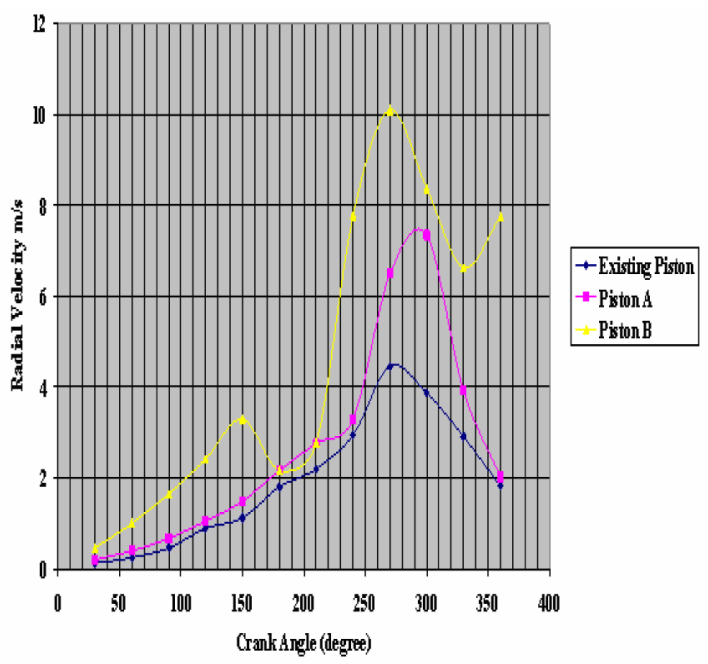

Figure12. Crank angle vs. radial velocity. 
In the piston analysis, the piston B with toroidal type combustion chamber was found to be much efficient than the other two piston configurations, with shallow depth chamber and the existing type chamber [6]. This study can be extended to analyze the piston configurations for the expansion and the exhaust strokes. The ignition delay, the magnitude of the premixed burn, the magnitude and timing of the diffusion burn can be analyzed in detail during the expansion stroke. The emission levels of the nitrous oxide and soot can be analyzed during the exhaust stroke.

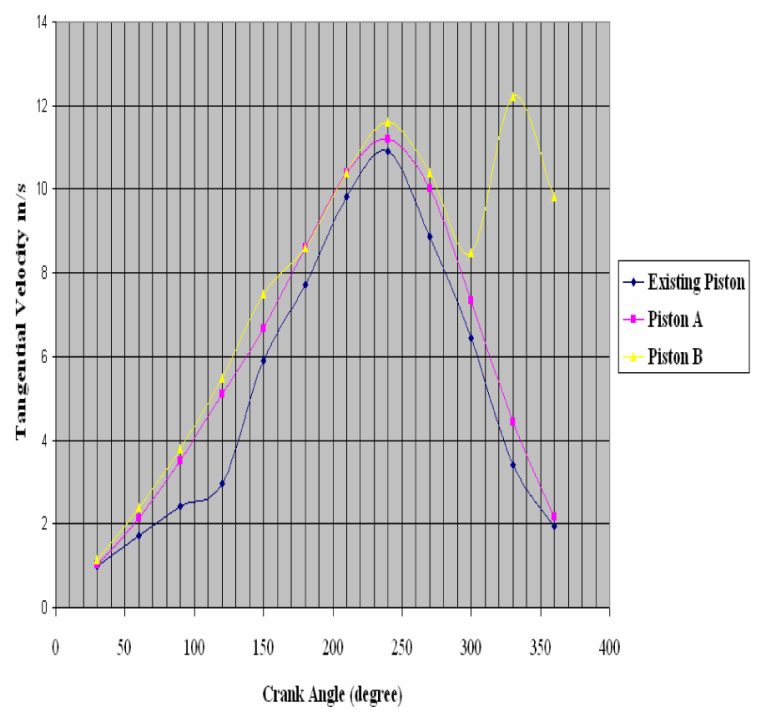

Figure13. Crank angle vs. tangential velocity.

Table 1. Piston A

\begin{tabular}{ccccc}
\hline $\begin{array}{l}\text { Crank Angle Velocity Radial } \\
\text { (degree) }\end{array}$ & $\begin{array}{c}\text { Tangential } \\
(\mathrm{m} / \mathrm{s})\end{array}$ & $\begin{array}{c}\text { Velocity }(\mathrm{m} / \mathrm{s}) \\
\text { Velocity }(\mathrm{m} / \mathrm{s})\end{array}$ & \\
\hline 30 & 2.21 & 0.197 & 1.03 & 0.216 \\
60 & 4.45 & 0.398 & 2.15 & 0.436 \\
90 & 6.66 & 0.67 & 3.43 & 0.652 \\
120 & 8.74 & 1.05 & 4.93 & 0.856 \\
150 & 10.5 & 1.49 & 6.68 & 1.029 \\
180 & 7.34 & 2.17 & 8.62 & 0.720 \\
210 & 8.3 & 2.76 & 10.4 & 0.814 \\
240 & 8.43 & 3.30 & 11.2 & 0.827 \\
270 & 10.2 & 6.49 & 10 & 1 \\
300 & 11.69 & 7.35 & 7.35 & 1.147 \\
330 & 11.78 & 3.92 & 4.42 & 1.156 \\
360 & 12.12 & 2.02 & 2.18 & 1.196 \\
\hline
\end{tabular}

Table 2. Piston B

\begin{tabular}{ccccc}
\hline $\begin{array}{l}\text { Crank Angle Velocity Radial } \\
(\text { degree })\end{array}$ & $\begin{array}{c}\text { Tangential } \\
(\mathrm{m} / \mathrm{s})\end{array}$ & $\begin{array}{l}\text { Swirl } \\
\text { Velocity (m/s) }\end{array}$ & $\begin{array}{l}\text { Velocity }(\mathrm{m} / \mathrm{s}) \\
\text { Ratio }\end{array}$ \\
\hline 30 & 2.31 & 0.469 & 1.14 & 0.216 \\
60 & 3.45 & 1.00 & 2.38 & 0.436 \\
90 & 4.20 & 1.65 & 3.81 & 0.338 \\
120 & 5.24 & 2.42 & 5.50 & 0.411 \\
150 & 6.6 & 3.30 & 7.49 & 0.513 \\
180 & 11.8 & 2.17 & 8.62 & 0.652 \\
210 & 12.2 & 2.78 & 10.4 & 0.922 \\
240 & 12.1 & 7.78 & 11.6 & 1.05 \\
270 & 9.44 & 10.1 & 10.4 & 1.186 \\
300 & 10.8 & 8.38 & 8.49 & 1.196 \\
330 & 13.3 & 6.63 & 12.2 & 1.30 \\
360 & 16.6 & 7.75 & 9.83 & 1.62 \\
\hline
\end{tabular}

Table 3. Existing Piston

\begin{tabular}{ccccl}
\hline $\begin{array}{l}\text { Crank Angle Velocity Radial } \\
\text { (degree) }\end{array}$ & $\begin{array}{c}\text { Tangential } \\
(\mathrm{m} / \mathrm{s})\end{array}$ & $\begin{array}{c}\text { Velocity }(\mathrm{m} / \mathrm{s}) \\
\text { Velocity }(\mathrm{m} / \mathrm{s})\end{array}$ & Swirl Ratio \\
\hline 30 & 1.598 & 0.121 & 0.98 & 0.192 \\
60 & 3.284 & 1.245 & 1.71 & 0.324 \\
90 & 4.243 & 0.460 & 2.41 & 0.416 \\
120 & 5.681 & 0.892 & 2.95 & 0.557 \\
150 & 7.344 & 1.12 & 5.9 & 0.72 \\
180 & 6.038 & 1.8 & 7.71 & 0.592 \\
210 & 8.884 & 2.2 & 9.82 & 0.871 \\
240 & 9.894 & 2.95 & 10.9 & 0.970 \\
270 & 10.40 & 4.46 & 8.88 & 1.02 \\
300 & 10.557 & 3.87 & 6.95 & 1.035 \\
330 & 10.679 & 2.91 & 3.42 & 1.047 \\
360 & 11.424 & 1.82 & 1.95 & 1.12 \\
\hline
\end{tabular}

\section{References}

1. Bedford F, Rutland C et al. (2000). Effects of direct water injection on DI diesel engine combustion, 1-10.

2. Zellat M, Duranti S et al. (2004). Advanced modeling of GDI and DI-diesel engines: investigations on combustion and wall heat transfer and comparison with experiments.

3. Dong M, Chen G et al. (2002). A preliminary CFD investigation of in-cylinder stratified EGR for spark ignition engines, SAE Technical Paper 2002-01-1734.

4. Simpson W T. Two-dimensional heat flow analysis applied to heat sterilization of ponderosa pine and Douglas-Fir square timbers, Wood and Fiber Science, vol 36(3), 459-464. 
5. Bensler H, Buhren F et al. (2012). CFD analysis of DI diesel engine combustion using a Flamelet Model.

6. Dibble R, Berkely et al. (2001). Modeling of HCCI and PCCI combustion process.

7. Schock H (2010). Thermoelectric conversion of waste heat to electric in an IC engine powered vehicle, Available From: http://www1.eere.energy.gov/vehiclesandfuels/pdfs/ merit_review_2010/solid-state_energy_conv/ace049_ schock_2010_o.pdf.

8. Chryssakis C A, Assanis D N et al. (2003). Fuel Spray Simulation of High-Pressure Swirl-Injector for DISI Engines and Comparison with Laser Diagnotic Measurements, SAE Technical Paper, 2003-01-0007.
9. McLandress A, Emerson R et al. (2010). Intake and in-cylinder flow modeling characterization of mixing and comparison with flow bench results.

10. Pulkrabek W W (2003). Engineering fundamentals of the Internal Combustion Engine, 2nd Edn., Person Education Publications 2nd Edn., 275-306..

11. Ferguason C R, and Kirkpatrick A T (1998). Internal Combustion Engines, Tata McGraw Hill Publishers.

12. Ganesan V (1998). Internal Combustion Engines, Tata McGraw Hill Publishers, 2nd Edn., 295-355.

13. Heywood J B (1998). Internal Combustion Engines, Tata McGraw Hill Publications , 682-692. 